\title{
Anthrax Outbreaks among Domestic Ruminants Associated with Butchering Infected Livestock and Improper Carcass Disposal in Three Districts of Uganda, 2016-2018
}

Fred Monje ( $\nabla$ fredmonje@musph.ac.ug )

Uganda Public Health Fellowship Program

Esther Kisaakye

Uganda Public Health Fellowship Program

Alex Riolexus Ario

Uganda Public Health Fellowship Program

Daniel Eurien

Uganda Public Health Fellowship Program

Vivian Ntono

Uganda Public Health Fellowship Program

Daniel Kadobera

Uganda Public Health Fellowship Program

Benon Kwesiga

Uganda Public Health Fellowship Program

\section{Steven Kabwama}

Uganda Public Health Fellowship Program

Deo Birungi Ndumu

National Animal Disease Diagnostic Epidemiology Centre

Lilian Bulage

Uganda Public Health Fellowship Program

Johanna S. Salzer

Centers for Disease Control and Prevention Division of High Consequence Pathogens and Pathology Julie R. Harris

Centers for Disease Control and Prevention

Bao-Ping Zhu

US Centers for Disease Control and Prevention

Research 
Keywords: Anthrax, livestock, Disease outbreaks, pooled analysis, Global Health Security, Uganda, Bacillus anthracis, Rapid diagnostic test

Posted Date: January 15th, 2020

DOl: https://doi.org/10.21203/rs.2.20910/v1

License: (c) (1) This work is licensed under a Creative Commons Attribution 4.0 International License. Read Full License 


\section{Abstract}

Background During January 2017-December 2018, multiple human anthrax outbreaks in Arua, Kween, and Kiruhura districts, Uganda were caused by exposure to domestic ruminants that died of anthrax. We investigated to determine the scope of anthrax outbreaks in domestic ruminants, identify possible exposures, and recommend evidence-based control measures.

Methods We defined a suspected case-animal as sudden death of a domestic ruminant with unclotted blood oozing from body orifices during January 2016-December 2018 in Arua, Kween and Kiruhura districts. A probable case-animal was a suspected case-animal with a positive rapid diagnostic test using the Active Anthrax Detect Rapid Diagnostic Test, and/or the microscopic identification of Gram-positive rods in biological samples. A case-kraal was defined as an enclosure of cattle/sheep or mixed species with $\geq 1$ suspected case-animal. We reviewed district veterinary records and actively searched for caselivestock. We conducted separate case-control studies in the affected districts to compare exposures between case-kraals and control-kraals (i.e., kraals with no suspected case-livestock during the same time period as the case-kraal), frequency-matched by village, with ratios of 1:1 in Arua, 1:4 in Kiruhura, and 1:2 in Kween. We estimated overall associations in all three districts using pooled analysis.

Results We identified 1,971 suspected case-livestock (attack rate [AR] $=1.4 / 1000)$ in $229(7.3 / 1,000)$ of 31,500 kraals. Cattle $(A R=2.1 / 1,000)$, goats $(A R=0.48 / 1,000)$, and sheep $(A R=0.10 / 1,000)$ were all affected. Of the three districts, Arua was the most affected $(A R=3.1 / 1,000)$, followed by Kween $(A R=1.8 / 1,000)$ and Kiruhura $(A R=0.065 / 1,000)$. The epidemic curve indicated continuous outbreaks in

Arua and Kween districts. Human outbreaks were reported during or after the onset of livestock outbreaks in all three districts. Having livestock that died of suspected anthrax butchered $<50 \mathrm{~m}$ from the kraal $(\mathrm{OR}=8.0 ; 95 \% \mathrm{Cl}=5.2-12)$ and improper livestock carcass disposal on/near the pastureland (OR=1.7, $95 \% \mathrm{Cl}=1.1-2.4$ ) before the outbreak were significant risk factors for being a case-kraal.

Conclusions Ugandan districts with human anthrax outbreaks had concurrent livestock anthrax outbreaks associated with nearby butchering and improper carcass disposal of livestock with suspected anthrax. We recommended anthrax vaccination for domestic ruminants, proper carcass disposal, increased surveillance for sudden livestock deaths, increased capacity for laboratory confirmation, and sensitization to livestock-keepers about anthrax control.

\section{Introduction}

Anthrax is a zoonotic disease caused by the Gram-positive spore-forming bacteria Bacillus anthracis (1). It is primarily a disease of domestic and wild herbivores, and presents as a peracute or acute condition, usually resulting in death (2). Livestock become infected when they either inhale or ingest B. anthracis spores from contaminated soil, contaminated water, or from carcasses of livestock that have died of anthrax (3). Upon entering the host, the spores germinate, multiply, and cause disease. The most susceptible species are cattle, sheep, and goats, but anthrax can also infect other mammals such as pigs, 
horses, dogs, cats, and primates $(4,5)$. The incubation period of anthrax in susceptible livestock is $1-14$ days after oral exposure (3). Infected livestock may have high fevers, blood-stained urine, bleeding from orifices, or no signs or symptoms at all (3). At death, livestock may demonstrate oozing blood from body orifices and rapid bloating of the carcass (6). It is postulated that the massive releases of capsulated bacilli from the lymphoid tissues, especially the spleen, leads to terminal septicemia and death within a day or two (7).

B. anthracis occurs in a vegetative form within the host, and a spore form in the environment (8). The spore form is extremely resistant to adverse conditions, and can survive for years in soil, or in the wool and hair of infected livestock. After an animal dies of anthrax, vegetative B. anthracis cells within the carcass sporulate and further contaminate the surrounding land, subsequently posing a risk to grazing livestock, such as cattle, goats, and sheep $(9,10)$. B. anthracis spores can remain viable on pastureland for decades. As a result, livestock outbreaks can be protracted, as exposures continue over many months or even years $(9,10)$. Human infections are most often associated with exposure to infected livestock or their products, such as meat, hides, bones, and other materials (11).

Anthrax has been documented in Uganda since at least 1918 (12), and livestock outbreaks have been reportable since 1959 (9). In recent years, outbreaks have occurred sporadically - including livestock and wildlife- and humans living in and around Queen Elizabeth National Park (13-15). Control of anthrax in livestock and, as a result, in humans, requires strong surveillance, annual vaccination of livestock, and rapid outbreak response involving immediate safe carcass disposal, ring vaccination of cattle, antibiotic treatment of sick livestock, and awareness campaigns $(9,16-18)$. However, in Uganda, no policy currently exists regarding annual routine vaccination against anthrax among livestock, although some farmers privately buy prophylactic antibiotics and vaccines for their livestock during suspected anthrax outbreaks.

During January 2017 to December 2018, human anthrax outbreaks were reported in three geographically distant districts of Uganda. Investigations of these human anthrax outbreaks revealed that they were caused by eating and handling meat from livestock that died of suspected anthrax (unpublished data). Although these findings suggested that outbreaks had also occurred recently or were occurring among domestic ruminants, no livestock cases were reported during this time. We investigated to identify corresponding anthrax outbreaks in domestic ruminants, to establish the scope of livestock infections, identify risk factors for infection, and recommend evidence-based prevention measures for future outbreaks.

\section{Methods}

\section{Study Area}

Arua District (coordinates at district center: $2.9960^{\circ} \mathrm{N}, 31.1710^{\circ} \mathrm{E}$ ) lies in northwestern Uganda, neighboring South Sudan, with an estimated population of 862,700 people $(19,20)$. Kiruhura District (coordinates at district center: $0.1928^{\circ} \mathrm{S}, 30.8039^{\circ} \mathrm{E}$ ) is located in western Uganda, with an estimated 
total population of 328,077 people (21). Kween District (coordinates at district center: $1.4439^{\circ} \mathrm{N}, 34.5971^{\circ}$ E) is located in eastern Uganda, neighboring Kenya, with an estimated population of 93,667 people (22).

The districts of Kween and Kiruhura are located within the "cattle corridor region" of Uganda (23), which is a broad zone stretching from southwestern to northeastern Uganda, dominated by pastoral rangelands. In Kiruhura and Kween Districts, approximately $60 \%$ of the population is engaged in livestock-rearing, including imported and indigenous cattle, goats, poultry, and pigs, and approximately $30 \%$ are involved in growing crops. This corridor has high rainfall variability, including periodic late seasonal onset of rains leading to drought (24). In Arua District, most of the population - approximately $90 \%$ - work in the crop sector, primarily growing maize, coffee, and beans, while fewer than $1 \%$ work in livestock-rearing.

\section{Case definition and case-finding}

We defined a suspected livestock case as sudden death of a domestic ruminant with unclotted blood emerging from body orifices from January 2016 to December 2018 in the districts of Arua, Kiruhura, and Kween. A probable case was a suspected case that tested positive for anthrax by the Active Anthrax Detect Rapid Diagnostic Test (AAD-RDT, described later) or identification of Gram-positive rods via microscopy of livestock tissue samples. To identify cases, we reviewed district veterinary anthrax records and conducted active community case-finding in the affected villages. We recorded the cases in a line list, which included signs and symptoms, livestock location, identification information, species, breed, date and site of death, method of carcass disposal, and vaccination status (ever vaccinated, and vaccinated during the past year).

\section{Descriptive epidemiology}

We described the characteristics of domestic ruminants (livestock) affected by anthrax by calculating the attack rates (AR) by species, sex, and breed. Denominator data for livestock populations were provided by the district veterinary offices. We evaluated the time of death using district-specific epidemic curves, and place of death using maps.

\section{Hypothesis generation interviews}

We conducted individual hypothesis-generating interviews with 229 leaders or owners of case-kraals (140 case-kraals in Arua, 22 case-kraals in Kiruhura, and 67 case-kraals in Kween). We collected information on potential exposures for livestock anthrax, including method and location of grazing (specifically, grazing near the riverbank during a drought), purchase of livestock from areas known to have anthrax outbreaks at the time of purchase, presence of a wildlife migration route on or near the pastureland, method of livestock carcass disposal, and vaccination status of livestock before an anthrax outbreak. Proper carcass disposal was defined as burial of a suspected anthrax-infected carcass at least six feet deep followed by disinfection of the land, while improper carcass disposal was defined as failure to bury a suspected anthrax-infected carcass at least six feet deep and/or failure to disinfect the site and/or leaving the carcass on the pastureland to rot or throwing the carcass in the river. 


\section{Case-control studies}

We conducted three separate case-control studies in Arua, Kiruhura, and Kween districts. The units of study were case- and control-kraals. In all three districts, a case-kraal was defined as one with at least one case-animal during January 2016-December 2018. A control-kraal was matched to a case-kraal by village and had not had any livestock that died suddenly with unclotted blood coming from body orifices during the same time period. For all three case-control studies, the same questionnaire tool was used, and questions were asked in the same way.

In Arua district, the field investigation was conducted during 10-24 July 2018 in Rigbo, Pawor, and Rhino sub-counties where human cases had been reported. We investigated exposures during January 2016July 2018. The case- and control-kraals were frequency-matched by village with a ratio of 1:1. In Kiruhura District, the field investigation was conducted during 23-28 October, 2018 in Engari, Burunga, Buremba, Nyakashashara, Kenshunga, and Kanoni sub-counties where human cases had been reported. The period of exposure investigated was during January 2016-October 2018. Case- and control-kraals were frequency-matched by village with a ratio of 1:4. Case-kraal to control-kraal ratios were determined based on the number of case-kraals in the district, with increasing numbers of control-kraals for districts with fewer case-kraals. In Kween District, the field investigation was conducted during 5-15 December 2018 in Ngenge sub-county, where human cases were reported. The period of exposure investigated was during January 2016-December 2018. Case- and control-kraals were frequency-matched by village with a ratio of $1: 2$.

We interviewed the heads or owners of the case- and control-kraals on the same exposures as used during hypothesis generation. We asked about these exposures with specific reference to the time period before the human outbreaks occurred in their respective districts.

\section{Environmental and laboratory investigations}

We assessed the environment to identify carcass disposal sites or remains, migration routes near the pastureland, and presence of natural features such as a rivers, swamps, or game reserve/game parks.

At the time of our investigation, livestock cases were still occurring. We were able to test samples from livestock carcasses from Arua, Kween and Kiruhura districts. We obtained nasal swabs, ear clips, and dried skin for testing using Gram stain and AAD-RDT (a lateral flow immunoassay) (25). These tests were used to identify probable livestock cases.

\section{Data analysis}

We conducted descriptive analysis overall and by district, using frequency distributions, percentages, and rates. We analyzed the case-control data for each district independently using Epi-info version 7.2.2.6 to identify the exposures of interest. Finally, we conducted a pooled analysis to estimate the summary odds ratios (OR) and their associated $95 \%$ confidence intervals (Cl) associated with the exposures of interest for all three districts, using Stata version 13.1. 


\section{Results}

\section{Findings from descriptive epidemiology and hypothesis-generating interviews}

We identified 1,971 case-livestock in 229 case-kraals in the three districts during 2016-2018. Of these, 1,600 (81\%) were from Arua District, 316 (16\%) were from Kween District, and 55 (2.8\%) were from Kiruhura District. Cattle were the most affected species in all districts (Attack rate $[A R] / 1000=2.1$ ), followed by goats $(A R / 1000=0.48)$ and sheep $(A R / 1000=0.10)$.

Of the three districts, Arua had the highest AR (3.1/1000), followed by Kween (1.8/1000), and Kiruhura $(0.065 / 1000)$ (Figure 1a). Although kraals are located throughout Arua district (not shown) all the casekraals in Arua were located along the Nile River (Figure 1b). In Kiruhura District, two clusters of casekraals were identified, one in Engari Sub-County and the other in Nyakashashara Sub-county; a few other sub-counties were also sporadically affected (Figure 1c). In Kween District, case-kraals were located in one sub-county close to the Pian Upe Game Reserve (Figure 1d).

During the study period, cases in Arua were reported from January 2016-July 2018; cases in Kween were reported from January-December 2018, and cases in Kiruhura were reported from May 2018-October 2018. The epidemic curve in Arua District suggested continuous, sustained exposures among livestock in the community (Figure 2a), while the epidemic curves in Kween and Kiruhura indicated outbreaks only during the year 2018 (Figures 2b-c). In Kiruhura, six sub-counties were affected in several clusters of infections (Figure 3). The corresponding epidemic curves by sub-county indicated that the livestock anthrax outbreak started in the neighboring Engari and Kanoni sub-counties before cases appeared in other sub-counties (Figure 4a-f).

Hypothesis-generating interviews with leaders of case-kraals from each district suggested that different districts might have different risk factors (Table 2). Leaders also mentioned that they sometimes provided antibiotics (in particular, oxytetracylines) to their livestock when they heard about outbreaks in neighboring kraals, with the hope of protecting their own kraal.

\section{Findings of case-control studies}

The district-specific case-control studies showed that, in Arua District, butchering the carcasses of livestock suspected to have died of anthrax on/near the pastureland was associated with 7.5 times higher odds of illness. In Kiruhura District, case-kraals had a 76 times higher odds of having suspected case-livestock butchered on/near the pastureland than control kraals. In Kween District, having suspected case-livestock butchered on/near the pastureland was associated with a 3.8-fold higher odds of being a case-kraal (Table 3).

When we asked the kraal leaders about livestock anthrax vaccination, they reported that none of the livestock in either the case- or control-kraals had ever been vaccinated against anthrax. 
In the pooled analysis, having suspected anthrax-infected dead livestock butchered on or near the pastureland before the outbreak was associated with 8-fold higher odds of being a case-kraal (Table 4).

\section{Environmental and laboratory investigation findings}

In all three districts affected by the outbreak, we observed carcasses of livestock reported to have died of suspected anthrax on the pastureland, as well as remains of wild herbivores suspected to have died of anthrax in game reserves near the pastureland. Community leaders in Ngenge Subcounty, Kween District reported that pastoralists who had come from Kenya during a drought in late 2017 in search of pasture and water had left dead livestock on the pastureland. Wildlife migration routes were also observed on the pastureland where outbreaks occurred. In Arua and Kween districts, we observed communal grazing with mixing of livestock from different kraals, while in Kiruhura District the livestock grazed in individual kraals. We observed livestock grazing near the riverbanks ( $<50 \mathrm{~m}$ from the water source) in Arua and Kween districts. In Kiruhura District, we observed carcass disposal sites on the pastureland.

Three specimens (swabs, ear clips, and dried skin) were collected from each of 21 carcasses identified during the study period. In total, 14 (67\%) carcasses were probable anthrax cases, as defined by positive AAD-RDT and Gram-positive rods identified by microscopy.

\section{Discussion}

Our epidemiologic, laboratory, and environmental investigations confirmed the existence of anthrax outbreaks in livestock populations in three Ugandan districts that reported human outbreaks. The outbreak in Arua District appeared to have been long-standing and continuous, at least dating back to 2016, whereas the outbreaks in Kiruhura and Kween districts appeared to have been smaller and more recent. Outbreaks in all three districts were associated with butchering dead livestock that died of suspected anthrax on/near the pastureland, and improper disposal of livestock carcasses. However, additional risk factors also differed to some extent between the districts: the Arua outbreak was associated with grazing livestock near the Nile River bank, the Kiruhura outbreak was associated with the construction of dams (not shown on the map), and the Kween outbreak was associated with having livestock pastureland close to a wildlife migration route.

Our findings of increased risk of livestock outbreaks after suspected anthrax-infected livestock were butchered on or disposed of on the pastureland are consistent with other studies $(12,18,26)$. Due to the long survival time of anthrax spores, a contaminated carcass can serve as a continuous source of infections for livestock in the surrounding area. Thus, an area that has substantial numbers of anthrax cases among livestock, such as Arua District during our study period, may face difficulty ending an outbreak if proper carcass disposal practices are not consistently followed. Proper carcass disposal involves digging a six-foot-deep hole for burial, in which the uppermost part of the carcass is $\geq 3$ feet below the original ground level. All the material around the carcass, including bedding, feed, and 
surrounding soil contaminated by the carcass are also put into the hole, followed by surface area disinfection with $10 \%$ formaldehyde. In Arua District in particular, the large number of suspected cases during 2016 may have served as sources of infection for the subsequent cases in 2017 and 2018. Because we did not assess cases beyond July 2018, it is not known if cases continued during that period.

Furthermore, in Arua District, grazing near the Nile riverbank during a drought was also associated with anthrax outbreaks. During drought, many livestock trek long distances and congregate at the Nile riverbank for pasture and water. It is possible that one animal could have died near the riverbank and contaminated the pastureland, making it a source of more widespread infections. The presence of carcasses in common areas where livestock mix widely - not just on their own pastureland - should be a signal to herders to avoid the area.

Our findings also indicated that anthrax exposures leading to the 2018 outbreaks in Kiruhura and Kween might have been fairly recent: although Kiruhura District has reported outbreaks previously (12), none had occurred during the past two years. However, during January 2018, a new dam was constructed in Kiruhura District, near pastureland. Digging of dams typically involves high levels of soil turnover, which can liberate buried anthrax spores (27). These spores could subsequently have contaminated the pastureland and served as sources of infection for both wildlife and domestic livestock in Kiruhura. The link between wildlife migration routes and infection observed in Kween District has also been demonstrated previously: other studies in Kenya and Tanzania have reported anthrax outbreaks at the human-livestock and livestock-wildlife interfaces $(28,29)$. The reported introduction of livestock from Kenya to graze in Kween during the 2017 drought could also have served as a potential source of infections. During that time period, there was an ongoing anthrax outbreak in the region of origin in Kenya (28). It is possible that livestock coming in from Kenya during that time period died of anthrax in Uganda; however, that remains unconfirmed.

In our study, cattle were more affected than goats and sheep. This is consistent with studies in both Kenya and China that identified cattle as being more affected by anthrax than goats and sheep $(26,28)$. Cattle ingest a large amount of soil from the ground when grazing, while goats typically browse on grass only; this may lead to higher levels of exposure among cattle, compared with goats. This characteristic is thought to be a major factor associated with different levels of infection among different species (9). Interestingly, the attack rates among male livestock were more than twice as high as among female livestock, and more than six times higher among domestic than imported livestock. The reasons for this are unknown, but may relate to the ways in which livestock ingest the spores during grazing or browsing, or variation in lethal doses among livestock (9).

Reported anthrax outbreaks among humans occurred concurrently with or subsequent to the start of the livestock outbreaks. Interestingly, in Arua district, human anthrax cases were not reported during 2016 or the first half of 2017, despite the deaths of many suspected case-livestock during this time. Indeed, in April 2016 alone, more than 200 livestock died of suspected anthrax in Arua. The reason for the lack of reported human cases during this time is unclear. It is possible that human cases - and, possibly, deaths 
- simply went unrecognized or unreported. It is also possible that at least some of the livestock deaths were due to other causes, or were due to anthrax but were not followed by human anthrax cases. Improved laboratory capacity to diagnose anthrax would facilitate improved understanding of the dynamics between livestock and human anthrax in Uganda.

Vaccination is generally considered a cost-effective prevention method for anthrax among livestock, and, as a result, among humans $(4,16,17,30,31)$. Although farmers reported using antibiotic prophylaxis during outbreaks (with a protective outcome for their livestock), none of the case-kraals were reportedly vaccinated against anthrax. This finding suggests a possible opportunity to promote routine annual vaccination in Uganda. Studies evaluating the cost-effectiveness of vaccination may help guide policy decisions

In 2017, anthrax was categorized as the most important of seven priority zoonoses in Uganda (33), and in June 2019, a national symposium was held to enhance One Health efforts to combat anthrax in Uganda. The symposium included: i) sharing of up-to-date spatial and temporal data on anthrax outbreaks in both livestock and humans in Uganda; ii) validating the national anthrax control strategy; iii) forming a National Anthrax Prevention and Control Technical Working Group (NAPCTWG) and iv) developing a roadmap for National Anthrax Prevention and Control Technical Working Group. Part of validating the national anthrax control strategy involved determining the best approaches to livestock vaccination, and filling the gaps in laboratory capacity. At the time of writing this paper, only the National Livestock Reference Laboratory and Uganda Virus Research Institute laboratory were able to confirm anthrax in Uganda. In addition, although One Health is recognized as a priority in Uganda, there are still gaps in implementing a harmonized approach to anthrax outbreaks. For example, as soon as the human anthrax outbreaks were reported, both the human anthrax and livestock anthrax could have been investigated together rather than separately. Indeed, the recognition by either human or livestock health staff of an anthrax outbreak should trigger notification to the corresponding human or livestock health counterpart, to enable coordination of investigations and concerted efforts towards effective interventions. Future efforts in Uganda should focus on these issues as the country improves its approach to combating anthrax.

\section{Limitations}

Our investigation had several limitations. Given that anthrax-infected livestock die suddenly, it is possible that livestock that may have died of anthrax in more rural areas went unnoticed. Additionally, some farmers may have failed to notice the absence of some members of their herd due to their large herd size. Failure to account for all anthrax-related livestock deaths in the area may have resulted in an underestimation of the scope of the outbreak. In addition, only a small subset of reported livestock deaths were tested, due to lack of available specimens and testing materials. Therefore, some of the suspected anthrax deaths might have been deaths due to other etiologies, and some anthrax deaths may have been unidentified. 


\section{Conclusions And Recommendations}

In conclusion, there was evidence of livestock anthrax outbreaks in Arua, Kiruhura, and Kween districts in Uganda concurrent with or preceding human outbreaks. Butchering anthrax-infected carcasses on the pastureland and improper disposal sites of contaminated carcasses on or near the pastureland was associated with elevated odds of being a case-kraal. As the outbreaks were still ongoing at the time of our investigation, we recommended that the Ministry of Agriculture, Animal Industry and Fisheries (MAAIF) and affected districts should conduct immediate vaccination of domestic ruminants in these high-risk areas and to follow annual anthrax vaccination schedules. We also recommended further efforts to increase the laboratory capacity to confirm livestock cases of anthrax and other causes of livestock deaths with human health importance. Additionally, we recommended sensitization of the various stakeholders, including the farmers, game wardens, livestock health workers and medical health workers about anthrax prevention and control. We also recommended increased surveillance and reporting of sudden livestock deaths and enforcement of livestock movement and quarantine, especially in known affected districts.

\section{Abbreviations}

AR: Attack Rate; CDC: US Centers for Disease Control and Prevention; AAD-RDT: Active Anthrax Detect Rapid Diagnostic Test; Cl: Confidence Interval; DVO: District Veterinary Officer; MAAIF: Ministry of Agriculture, Animal Industry and Fisheries; MoH: Ministry of Health; NADDEC: National Animal Disease Diagnostic Epidemiology Centre; OR: Odds Ratio; PEPFAR: President's Emergency Plan for AIDS Relief.

\section{Declarations}

\section{Ethical approval and Consent to participate}

The National Animal Disease Diagnostic and Epidemiology Centre of the Ministry of Agriculture, Animal Industry and Fisheries and the District Veterinary Officers of Arua, Kiruhura, and Kween districts gave the permission to conduct the investigations. The Center for Global Health, US Centers for Disease Control and Prevention (CDC) determined that this investigation was public health practice with the primary intent of disease control; therefore, it was not considered research. Thus, we do not need any other permission from Institutional Review Board according to the Ugandan policies and guidelines and are free to publish the work. We obtained verbal informed consent from leaders or owners of case- and control-kraals before interviews began. Participants were told that their participation in the study was voluntary and refusal to participate would not result in any negative consequences. During data analysis, we used unique identifiers to ensure confidentiality of the information provided by livestock owners. 


\section{Availability of supporting data}

The datasets upon which our findings are based belong to the Uganda Public Health Fellowship Program. For confidentiality reasons, the datasets are not publicly available. However, the data sets can be availed upon reasonable request from the corresponding author and with permission from the Uganda Public Health Fellowship Program.

\section{Competing interests}

The authors declare that they had no competing interests

\section{Funding}

This project was supported by the President's Emergency Plan for AIDS Relief (PEPFAR) through the US Centers for Disease Control and Prevention Cooperative Agreement number GH001353-01 through Makerere University School of Public Health to the Uganda Public Health Fellowship Program, MoH. Its contents are solely the responsibility of the authors and do not necessarily represent the official views of the US Centers for Disease Control and Prevention, Makerere University School of Public Health, or the $\mathrm{MoH}$.

\section{Authors' contributions}

FM designed the study, and took lead in data collection, analysis, interpretation and drafting of the manuscript. EK, VN and DE participated in data collection and analysis; DBN provided expertise on the design of the study, data collection tools and livestock anthrax laboratory testing; DK, ARA participated in the design, analysis and interpretation of the data; BK supervised data collection, analysis, and interpretation of the study in the affected districts. SK provided guidance on pooled analysis. LB supervised the design and drafting of the manuscript. JSS, JH and BPZ reviewed the manuscript for intellectual content and approved it for publication. All the authors reviewed the manuscript to ensure scientific integrity and intellectual content.

\section{Acknowledgements}


We appreciate Uganda's Ministry of Agriculture, Animal Industry and Fisheries, Ministry of Health, and the district local governments of Arua, Kiruhura, and Kween, for providing access to the anthrax data and laboratory testing of livestock samples. We express special gratitude to the One Health Office- Infectious Disease Institute (West Nile region) for the technical support during data collection in Arua. We are grateful to InBios for providing the RDTs free of cost for the outbreak investigation. Last but not least, we thank cohort 2018 Fellows of Uganda Public Health Fellowship Program for the technical support during the execution of this investigation

\section{Authors' information}

Dr. Fred Monje holds a Masters in Veterinary Preventive Medicine and a bachelor's degree in Veterinary Medicine from Makerere university, Kampala, Uganda. Fred is a former FETP-V awardee of a 2-year AFENET Scholarship that led to his Master's degree in Veterinary Preventive Medicine of Makerere University. Fred is currently an Advanced Field Epidemiology Fellow with Uganda Public Health Fellowship Program (PHFP). The fellowship program aims at providing additional skill training and workrelated competences in applied epidemiology, effective communication, management and leadership and public health programming with emphasis in solving issues of public health concern by linking them to timely action. Prior to joining the fellowship program, Fred was a Senior Veterinary Inspector and One Health Focal Person for the Ministry of Agriculture, Animal Industry and Fisheries where he played a key role in the establishment of the National One Health Platform in Uganda. Fred has participated and successfully investigated a number of disease outbreaks in Uganda using a One Health Approach such as Anthrax, Marburg, Ebola, Rift Valley Fever, Crimean Congo Haemorrhagic Fever, Rabies, and Brucellosis among others.

\section{References}

1. Anthrax Pathogenesis | Annual Review of Microbiology [Internet]. [cited 2018 Sep 28]. Available from: https://www.annualreviews.org/doi/abs/10.1146/annurev-micro-091014-104523

2. Cizauskas CA, Bellan SE, Turner WC, Vance RE, Getz WM. Frequent and seasonally variable sublethal anthrax infections are accompanied by short-lived immunity in an endemic system. Journal of Animal Ecology. 2014 Sep 1;83(5):1078-90.

3. Anthrax in Humans and Animal - World Health Organization - Google Books [Internet]. [cited 2018 Nov 12].

4. Awoonor-Williams J, Apanga P, Anyawie M, Abachie T, Boidoitsiah S, Opare J, et al. Anthrax Outbreak Investigation among Humans and Animals in Northern Ghana: Case Report. International Journal of TROPICAL DISEASE \& Health. 2016 Jan 10;12(2):1-11.

5. Chen H, Bao W, Wang Y, Zhang K, Wang F. Clinical and epidemiological investigation of a fatal anthrax case in China. 1. 2015 Feb 19;9(02):214-7. 
6. Department of Economic Development J. Anthrax in animals [Internet]. [cited 2018 Nov 10]. Available from: http://agriculture.vic.gov.au/agriculture/pests-diseases-and-weeds/livestock-diseases/generallivestock-diseases/anthrax-in-animal

7. Smith IM. A brief review of anthrax in domestic animals. Postgraduate Medical Journal. 1973 Aug 1;49(574):571-2.

8. Goel AK. Anthrax: A disease of biowarfare and public health importance. World J Clin Cases. 2015 Jan 16;3(1):20-33.

9. World Health Organization, International Office of Epizootics, Food and Agriculture Organization of the United Nations, editors. Anthrax in humans and lanimals. 4th ed. Geneva, Switzerland: World Health Organization; 2008. 208 p.

10. Carlson CJ, Getz WM, Kausrud KL, Cizauskas CA, Blackburn JK, Carrillo FAB, et al. Spores and soil from six sides: interdisciplinarity and the environmental biology of anthrax (Bacillus anthracis). Biological Reviews [Internet]. [cited 2018 Sep 19];0(0). Available from: https://onlinelibrary.wiley.com/doi/abs/10.1111/brv.12420

11. Swartz MN. Recognition and Management of Anthrax - An Update. New England Journal of Medicine. 2001 Nov 29;345(22):1621-6.

12. Taylor JA. Anthrax in Ankole, Uganda. Transactions of the Royal Society of Tropical Medicine and Hygiene [Internet]. 1923 [cited 2018 Sep 18];17(1). Available from: https://www.cabdirect.org/cabdirect/abstract/19232901850

13. Bere RM. Queen Elizabeth National Park: Uganda The Hippopotamus Problem and Experiment. Oryx. 1959 Dec;5(3):116-24.

14. Wafula MM, Patrick A, Charles T. Managing the 2004/05 anthrax outbreak in Queen Elizabeth and Lake Mburo National Parks, Uganda. African Journal of Ecology. 2008 Mar 1;46(1):24-31.

15. Coffin JL, Monje F, Asiimwe-Karimu G, Amuguni HJ, Odoch T. A One Health, participatory epidemiology assessment of anthrax (Bacillus anthracis) management in Western Uganda. Social Science \& Medicine. 2015 Mar 1;129:44-50.

16. Kracalik I, Malania L, Broladze M, Navdarashvili A, Imnadze P, Ryan SJ, et al. Changing livestock vaccination policy alters the epidemiology of human anthrax, Georgia, 2000-2013. Vaccine. 2017 Nov 1;35(46):6283-9.

17. Vieira AR, Salzer JS, Traxler RM, Hendricks KA, Kadzik ME, Marston CK, et al. Enhancing Surveillance and Diagnostics in Anthrax-Endemic Countries. Emerg Infect Dis. 2017 Dec;23(Suppl 1):S147-53.

18. Thapa NK, Wangdi K, Dorji T, Dorjee J, Marston CK, Hoffmaster AR. Investigation and Control of Anthrax Outbreak at the Human-Animal Interface, Bhutan, 2010. Emerg Infect Dis. 2014 Sep;20(9):1524-6.

19. Arua POB. Arua District local government statistical abstract. :97.

20. Arua District [Internet]. West Nile Web. [cited 2018 Sep 20]. Available from: https://www.westnileweb.com/districts/arua-district 
21. Kiruhura (District, Uganda) - Population Statistics, Charts, Map and Location [Internet]. [cited 2019 Jun 13]. Available from: https://www.citypopulation.de/php/uganda-admin.php?adm2id=065

22. KWEEN.pdf [Internet]. [cited 2019 Feb 21]. Available from: https://www.ubos.org/wpcontent/uploads/publications/2014CensusProfiles/KWEEN.pdf

23. Figure 1: Map of Uganda showing the cattle corridor (shaded). In the... [Internet]. ResearchGate. [cited 2019 Feb 21]. Available from: https://www.researchgate.net/figure/Map-of-Uganda-showing-thecattle-corridor-shaded-In-the-South-and-central-districts_fig1_315535575

24. Climate change vulnerability and adaptation in Uganda's cattle corridor | Adaptation at Scale in SemiArid Regions [Internet]. [cited 2019 Apr 11]. Available from: http://www.assar.uct.ac.za/news/climatechange-vulnerability-and-adaptation-uganda\%E2\%80\%99s-cattle-corridor

25. Kolton CB, Marston CK, Stoddard RA, Cossaboom C, Salzer JS, Kozel TR, et al. Detection of Bacillus anthracis in animal tissues using InBios active anthrax detect rapid test lateral flow immunoassay. Letters in Applied Microbiology [Internet]. 2019 Mar 28 [cited 2019 Apr 12]; Available from: https://onlinelibrary.wiley.com/doi/abs/10.1111/lam.13134

26. Chen W-J, Lai S-J, Yang Y, Liu K, Li X-L, Yao H-W, et al. Mapping the Distribution of Anthrax in Mainland China, 2005-2013. PLOS Neglected Tropical Diseases. 2016 Apr 20;10(4):e0004637.

27. Shadomy S, Idrissi AE, Raizman E, Bruni M, Palamara E, Pittiglio C, et al. Anthrax outbreaks: a warning for improved prevention, control and heightened awareness. 2016; 37:8. Vol. 37. September 2016. Empress-Livestock@fao.org/www.fao.org/ag/empress

28. Muturi M, Gachohi J, Mwatondo A, Lekolool I, Gakuya F, Bett A, et al. Recurrent Anthrax Outbreaks in Humans, Livestock, and Wildlife in the Same Locality, Kenya, 2014-2017. Am J Trop Med Hyg. 2018 Oct;99(4):833-9.

29. Mwakapeje ER, Høgset S, Fyumagwa R, Nonga HE, Mdegela RH, Skjerve E. Anthrax outbreaks in the humans - livestock and wildlife interface areas of Northern Tanzania: a retrospective record review 2006-2016. BMC Public Health. 2018 05;18(1):106.

30. Lepheana RJ, Oguttu JW, Qekwana DN. Temporal patterns of anthrax outbreaks among livestock in Lesotho, 2005-2016. PLOS ONE. 2018 Oct 24;13(10):e0204758.

31. Bahiru G, Bekele A, Seraw B, Boulanger L, Ali A. Human and animal anthrax in Ethiopia: A retrospective record review 2009-2013. Ethiopian Veterinary Journal. 2016 Jan 1;20(2):76-85-85.

32. Kracalik IT, Kenu E, Ayamdooh EN, Allegye-Cudjoe E, Polkuu PN, Frimpong JA, et al. Modeling the environmental suitability of anthrax in Ghana and estimating populations at risk: Implications for vaccination and control. PLOS Neglected Tropical Diseases. 2017 Oct 13;11(10):e0005885.

33. Sekamatte M, Krishnasamy V, Bulage L, Kihembo C, Nantima N, Monje F, et al. Multisectoral prioritization of zoonotic diseases in Uganda, 2017: A One Health perspective. PLOS ONE. 2018 May 1;13(5):e0196799.

\section{Tables}


Table 1: Attack Rates $(/ 1,000)$ by livestock type in anthrax-affected districts of Arua, Kween and Kiruhura: 2016-2018

\begin{tabular}{llrll}
\hline District & Livestock type & Cases & Total Population & AR/1000 \\
\hline By District & & & & \\
\hline Arua & Cattle & 1,322 & 144,090 & 9.2 \\
& Goat & 268 & 314,832 & 0.85 \\
& Sheep & 10 & 54,693 & 0.18 \\
& All livestock & 1600 & 513,615 & 3.1 \\
Kween & Cattle & 285 & 95,560 & 2.9 \\
& Goat & 30 & 75,073 & 0.39 \\
& Sheep & 1 & 9,850 & 0.10 \\
& All livestock & 316 & 180,483 & 1.8 \\
Kiruhura & Cattle & 54 & 570,519 & 0.095 \\
& Goat & 1 & 230,468 & 0.0043 \\
& Sheep & 0 & 42,441 & 0 \\
& All livestock & 55 & 843,428 & 0.065 \\
\hline By sex & & & & \\
\hline \multirow{5}{*}{ By source } & Male & 330 & 94,362 & 3.5 \\
& Female & 1,641 & $1,080,843$ & 1.5 \\
\hline & Local & & \\
\hline & Imported & 1,918 & $1,014,818$ & 1.9 \\
& & 53 & 160,387 & 0.3 \\
\hline
\end{tabular}

Table 2: Distribution of possible exposure factors from hypothesis generation interviews with leaders of case-kraals in districts of Arua, Kiruhura and Kween, Uganda: 2016-2018 xposures

\begin{tabular}{|c|c|c|c|}
\hline 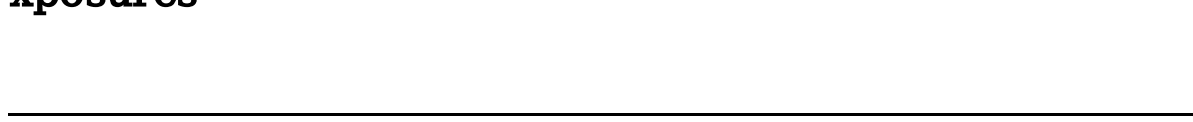 & $\begin{array}{l}\text { Arua, } n=140 \\
(\%)\end{array}$ & $\begin{array}{l}\text { Kiruhura, } \\
\mathrm{n}=22(\%)\end{array}$ & $\begin{array}{l}\text {, Kween, } \\
n=67(\%)\end{array}$ \\
\hline ead livestock butchered on or near the pastureland & 85 & 73 & 73 \\
\hline razed livestock near the river bank during drought & 84 & 5 & 33 \\
\hline resence of migration route near the pastureland & 62 & 77 & 92 \\
\hline $\begin{array}{l}\text { igging activities taking place on or near the pastureland } \\
\text { ncluding dams) }\end{array}$ & 46 & 18 & 37 \\
\hline arcass disposal sites on or near the pastureland & 31 & 59 & 85 \\
\hline ot vaccinating livestock against anthrax in past year & 100 & 100 & 100 \\
\hline
\end{tabular}


Table 3: Case-kraal exposure factors during outbreaks: Arua, Kiruhura and Kween Districts, Uganda, 2016-2018 


\begin{tabular}{|c|c|c|c|c|c|}
\hline & $\begin{array}{c}\# \\
\text { case- } \\
\text { kraals }\end{array}$ & $\begin{array}{c}\# \\
\text { contro } \\
\text { kraals }\end{array}$ & $\begin{array}{r}\% \\
\text { case- } \\
\text { kraals }\end{array}$ & $\begin{array}{l}\text { \% } \\
\text { control- } \\
\text { kraals }\end{array}$ & $\begin{array}{l}\text { OR } \\
(95 \% \\
\text { CI) } \\
\end{array}$ \\
\hline Arua District & 110 & 110 & 100 & 100 & \\
\hline $\begin{array}{l}\text { Dead Livestock butchered on or near the } \\
\text { pastureland }\end{array}$ & 67 & 33 & 61 & 30 & $\begin{array}{l}7.5 \\
(3.9- \\
14)^{*}\end{array}$ \\
\hline Grazed livestock near river bank during drought & 55 & 45 & 50 & 41 & $\begin{array}{l}2.3 \\
(1.2- \\
4.4)^{*}\end{array}$ \\
\hline $\begin{array}{l}\text { Livestock treated with antibiotics upon hearing } \\
\text { rumors of anthrax outbreaks in the neighborhood }\end{array}$ & 14 & 86 & 13 & 78 & $\begin{array}{l}0.029 \\
(0.014 \\
- \\
0.061)\end{array}$ \\
\hline Kiruhura District & 22 & 88 & 100 & 100 & \\
\hline Dead livestocks butchered on or near pastureland & 16 & 3 & 73 & 3.4 & $\begin{array}{l}76(17- \\
330)^{*}\end{array}$ \\
\hline Carcass disposal sites on or near pastureland & 13 & 10 & 59 & 11 & $\begin{array}{l}11 \\
(3.8- \\
33)^{*}\end{array}$ \\
\hline $\begin{array}{l}\text { Disturbed earth to build dam on or near } \\
\text { pastureland }\end{array}$ & 4 & 4 & 18 & 4.5 & $\begin{array}{l}4.7 \\
(1.1- \\
20)^{*}\end{array}$ \\
\hline Migration route near pastureland grazing sites & 17 & 54 & 77 & 61 & $\begin{array}{l}2.1 \\
(0.76- \\
6.3)\end{array}$ \\
\hline Grazed livestock near riverbank during drought & 1 & 6 & 4.5 & 6.8 & $\begin{array}{l}0.65 \\
(0.074- \\
5.7)\end{array}$ \\
\hline Kween District & 67 & 128 & 100 & 100 & \\
\hline $\begin{array}{l}\text { Migration route near } \\
\text { grazing sites }\end{array}$ & 63 & 99 & 94 & 77 & $\begin{array}{l}5.6 \\
(1.9- \\
16)^{*}\end{array}$ \\
\hline $\begin{array}{l}\text { Dead livestocks butchered near or on the } \\
\text { pastureland }\end{array}$ & 51 & 47 & 76 & 37 & $\begin{array}{l}3.8 \\
(1.9- \\
7.5)^{*}\end{array}$ \\
\hline Carcass disposal sites near or on the pastureland & 47 & 73 & 70 & 57 & $\begin{array}{l}2.0 \\
(1.1- \\
3.7)^{*}\end{array}$ \\
\hline Digging activities near or on the pastureland & 26 & 33 & 39 & 26 & $\begin{array}{l}1.3 \\
(0.71- \\
2.6)\end{array}$ \\
\hline $\begin{array}{l}\text { Grazed livestock near the riverbank during } \\
\text { drought }\end{array}$ & 21 & 48 & 31 & 38 & $\begin{array}{l}0.82 \\
(0.44- \\
1.5)\end{array}$ \\
\hline
\end{tabular}

* Exposures significant at $\mathrm{p}<0.05$ 
$\mathrm{OR}=$ Odds ratio using conditional logistic regression to account for matched study design; $\mathrm{CI}=$ confidence interval.

Table 4: Pooled analysis results showing association of exposures and livestock anthrax infection in districts of Arua, Kiruhura and Kween, Uganda: 2016-2018

\begin{tabular}{|c|c|c|c|c|}
\hline Exposures & Study Name & $\begin{array}{l}\text { Effect } \\
\text { Size (OR) }\end{array}$ & $\begin{array}{l}95 \% \\
\mathrm{CI}\end{array}$ & $\begin{array}{l}\text { Weight } \\
\text { (\%) }\end{array}$ \\
\hline \multirow{4}{*}{$\begin{array}{l}\text { Dead livestock butchered near or on the } \\
\text { pastureland }\end{array}$} & Arua & 7.1 & $3.8-$ & 49 \\
\hline & Kiruhura & 76 & $17-$ & 2.1 \\
\hline & Kween & 5.9 & $3.0-$ & 49 \\
\hline & $\begin{array}{l}\text { pooled OR (for } 3 \\
\text { districts) }\end{array}$ & 7.9 & $\begin{array}{l}5.2- \\
12\end{array}$ & $100 *$ \\
\hline \multirow{4}{*}{$\begin{array}{l}\text { Carcass disposal sites near or on the } \\
\text { pastureland }\end{array}$} & Arua & 0.88 & $0.50-$ & 61 \\
\hline & Kiruhura & 11 & $3.9-$ & 3.9 \\
\hline & Kween & 1.9 & $\begin{array}{l}1.1- \\
3.7\end{array}$ & 35 \\
\hline & $\begin{array}{l}\text { pooled OR (for } 3 \\
\text { districts) }\end{array}$ & 1.7 & $\begin{array}{l}1.1- \\
2.4\end{array}$ & $100 *$ \\
\hline \multirow{4}{*}{$\begin{array}{l}\text { Migration routes on or near the } \\
\text { pastureland grazing sites }\end{array}$} & Arua & 0.57 & $0.33-$ & 79 \\
\hline & Kiruhura & 2.1 & $\begin{array}{l}0.72- \\
6.3\end{array}$ & 12 \\
\hline & Kween & 5.6 & $\begin{array}{l}1.9- \\
16\end{array}$ & 9 \\
\hline & $\begin{array}{l}\text { pooled OR (for } 3 \\
\text { districts) }\end{array}$ & 1.2 & $\begin{array}{l}0.82- \\
1.86\end{array}$ & 100 \\
\hline \multirow[t]{4}{*}{$\begin{array}{l}\text { Grazed livestock near the river bank } \\
\text { during drought }(<100 \mathrm{~m})\end{array}$} & Arua & 2.3 & $\begin{array}{l}1.2- \\
4.4\end{array}$ & 34 \\
\hline & Kiruhura & 0.65 & $\begin{array}{l}0.07- \\
5.7\end{array}$ & 6.3 \\
\hline & Kween & 0.87 & $\begin{array}{l}0.47- \\
1.6\end{array}$ & 59 \\
\hline & $\begin{array}{l}\text { pooled OR (for } 3 \\
\text { districts) }\end{array}$ & 1.34 & $\begin{array}{l}0.87- \\
2.1\end{array}$ & 100 \\
\hline \multirow[t]{4}{*}{$\begin{array}{l}\text { Digging activities on or near the } \\
\text { pastureland }\end{array}$} & Arua & 0.41 & $\begin{array}{l}0.24- \\
0.71\end{array}$ & 74 \\
\hline & Kiruhura & 4.7 & $\begin{array}{l}1.1- \\
20\end{array}$ & 2.3 \\
\hline & Kween & 1.9 & $\begin{array}{l}1.0- \\
3.6\end{array}$ & 24 \\
\hline & $\begin{array}{l}\text { pooled OR (for } 3 \\
\text { districts) }\end{array}$ & 0.88 & $\begin{array}{l}0.6- \\
1.3 \\
\end{array}$ & 100 \\
\hline
\end{tabular}




\section{Figures}

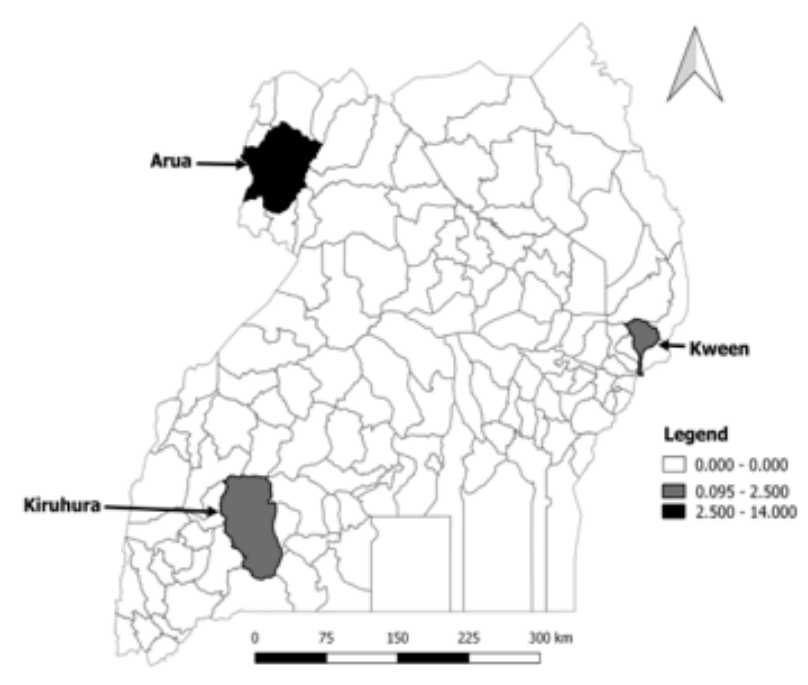

a) Arua, Kiruhura, and Kween districts where anthrax outbreaks occurred

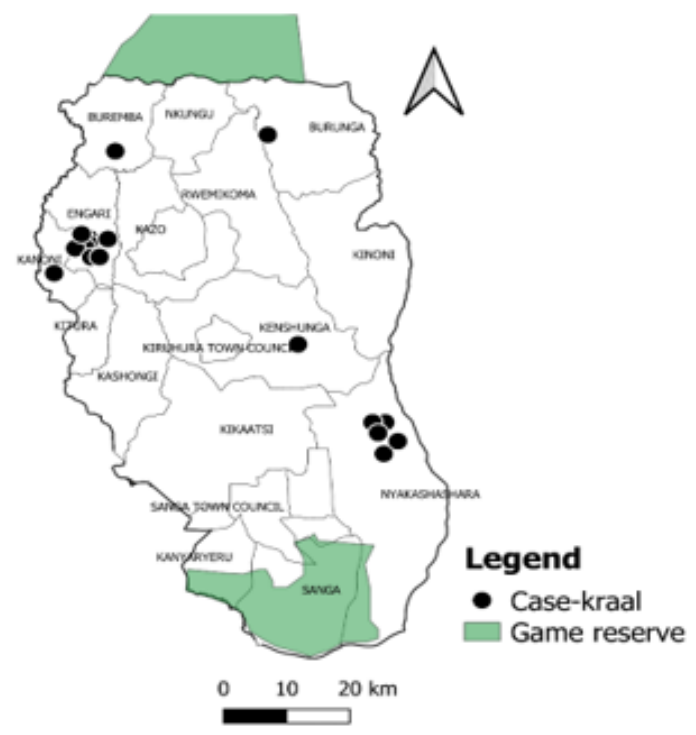

c) Locations of case-kraals in Kiruhura District

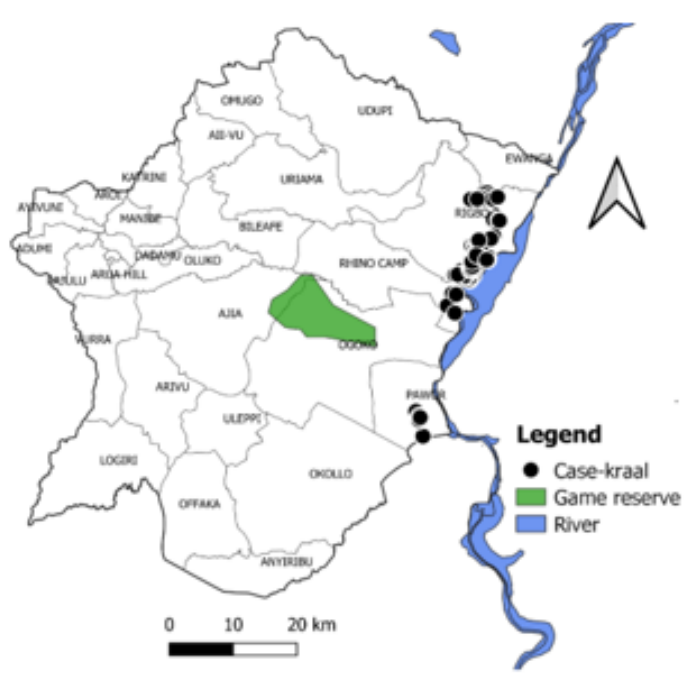

b) Locations of case-kraals in Arua District

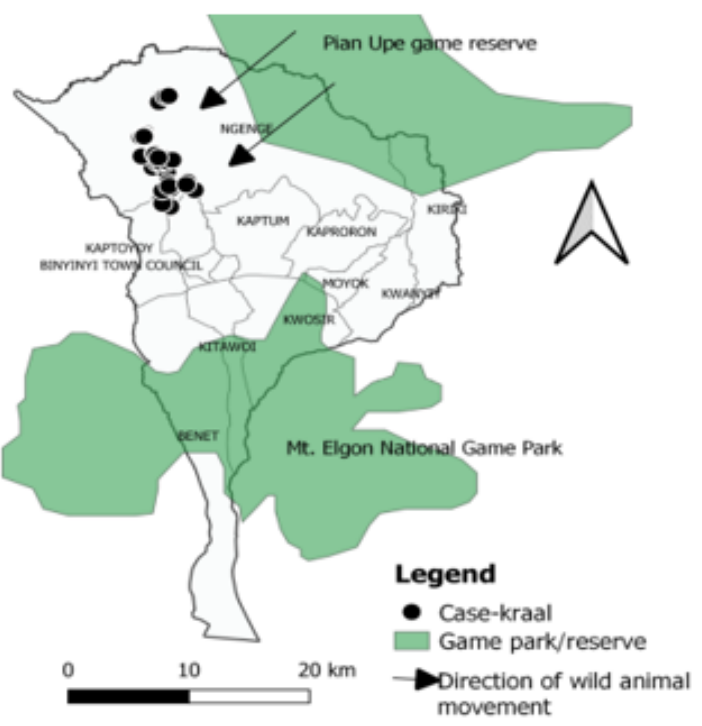

d) Locations of case-kraals in Kueen District

\section{Figure 1}

Spot maps of case-kraals in the districts of Arua, Kween, and Kiruhura, Uganda: 2016-2018 


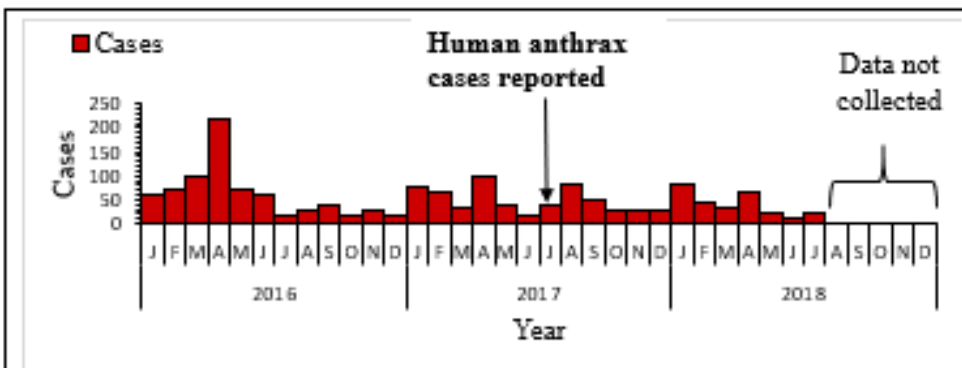

a) Arua District

\section{ם Cases}
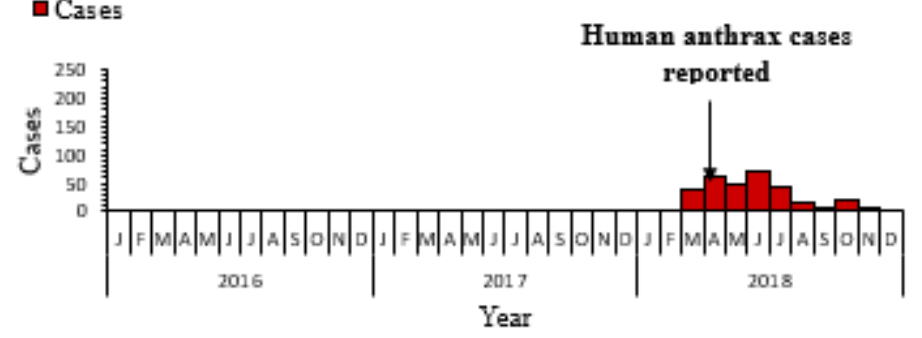

b) Kreen District

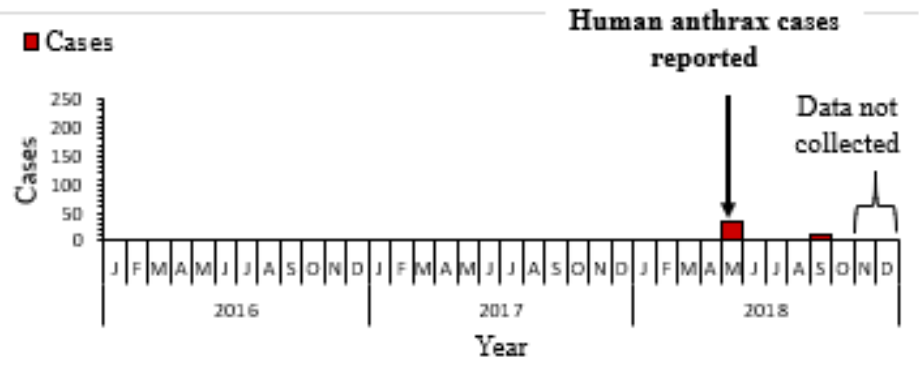

c) Kiruhura District

Figure 2

Stratified epidemiological curves of livestock anthrax outbreaks in districts of Arua, Kween and Kiruhura, Uganda: 2016-2018 


\section{Legend}

Attack Rates $/ 10000$

$0.0-0.0$

$0.0-0.4$

$0.4-2.7$

$2.7-13.0$

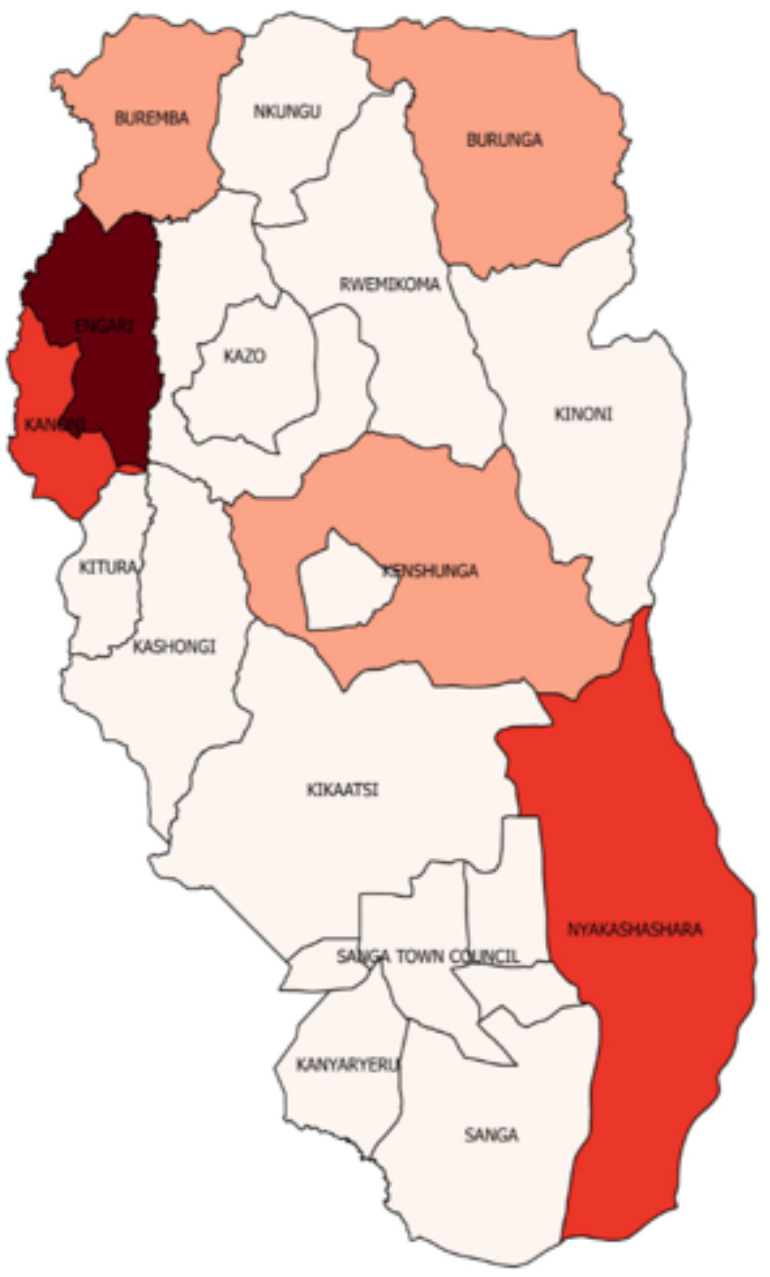

2

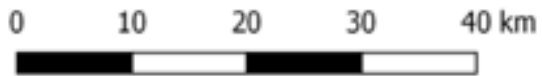

Figure 3

Attack Rates per Subcounty of livestock anthrax in Kiruhura District, May-October, 2018 

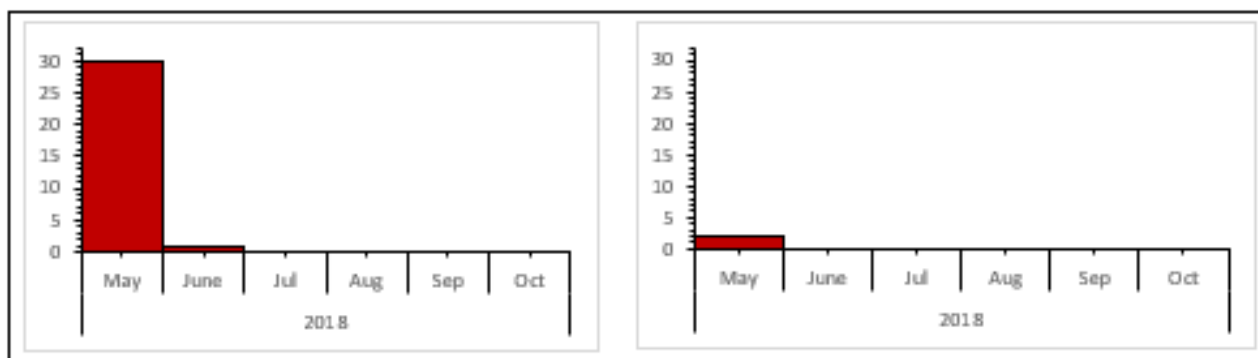

a) Engari Subcounty

b) Kanoni Subcounty

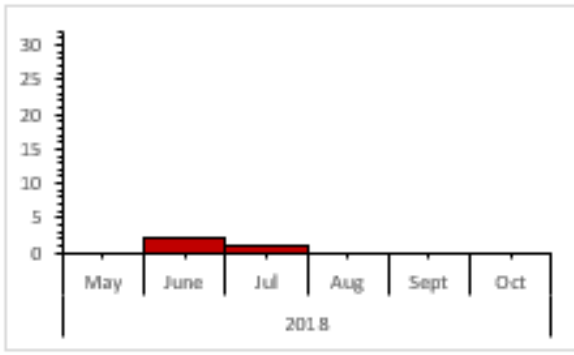

c) Burunga Subcounty

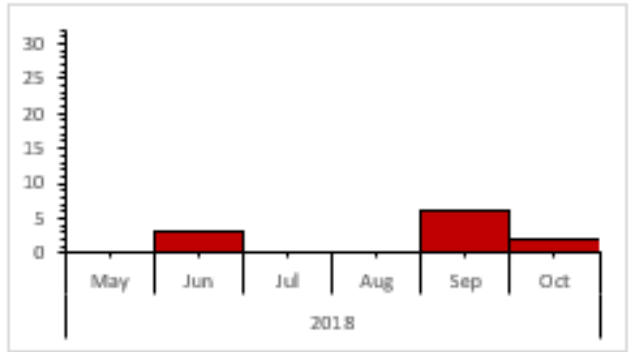

d) Kenshunga Subcounty

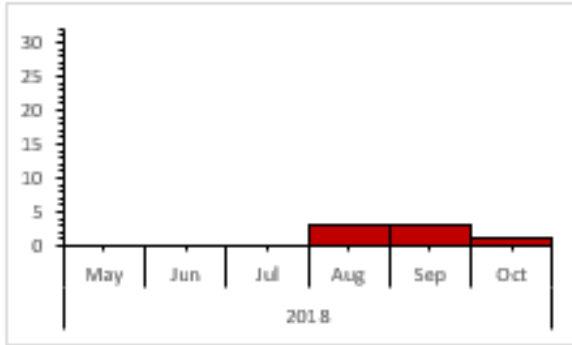

e) Nxabasbasbaca Subcounty

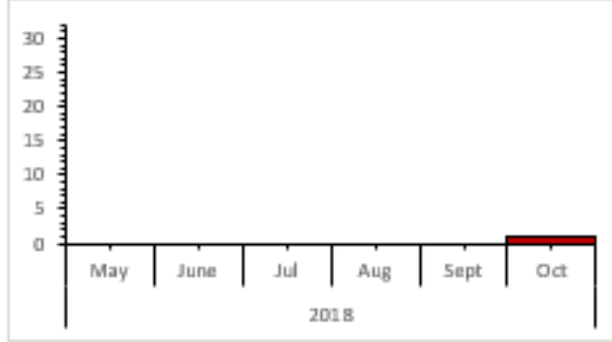

f) Buxembs Subcounty

Figure 4

Stratified epidemiological curves of livestock anthrax outbreaks per Subcounty in Kiruhura District, Uganda: 2016-2018 